\title{
Making Space for Sociability: How Children Animate the Public Realm in Suburbia
}

Mary P. Corcoran, Jane Gray, and Michel Peillon

\begin{abstract}
This article aims to demonstrate the significant role children play in new suburban communities, and in particular, the extent to which their circuits of sociability contribute to social cohesion in the suburbs. The discussion is located within the field of sociology of childhood, which argues that children are active agents who help to create and sustain social bonds within their neighborhoods. Drawing on focus group discussions and short essays by children on "The place where I live," we paint a picture of how suburban life is interpreted and experienced from a child's perspective. We argue that children develop a particular suburban sensibility that structures their view of their estate, the wider neighborhood, and the metropolitan core. Although children express considerable degrees of satisfaction with suburban life, they are critical of the forces that increasingly limit their access to suburban public space.
\end{abstract}

\section{KEYWORDS}

anti-urban ideology, children, neighborhood, public space, sociability

"I live in a housing estate ... There are five other estates in that area. All the houses are semi-detached. My friends' houses are only down the road from me. There are four green areas for playing on. I have lived in that estate for nearly thirteen years now. There is a shop, a Fiat garage, a driving centre and the cinema is only a fifteen minutes walk from me. You would find dogs, cats and hedgehogs." (School child, Mullingar)

It is only relatively recently that children's voices have come to be heard within mainstream sociology. Traditional views of the socialization process reinforced the notion that children, in the context of their families and personal communities, play a passive role. Newer literature within the field of sociology of childhood has challenged passive conceptualizations of the child and argued for an interpretive reproduction approach. Such an approach holds that "children are not formed by natural and social forces but rather ... they inhabit a world of meaning created by themselves and through their interactions with

Nature and Culture 4(1), Spring 2009: 35-56 @ Berghahn Journals doi:10.3167/nc.2009.040103 
adults" (James, Jenks, and Prout et al. 1998: 28). Or as Corsaro puts it: "Children are active, creative social agents who produce their own unique children's cultures while simultaneously contributing to the production of adult societies" (2005: 3). The traditional linear developmental model of childhood emphasizes stages of socialization and the progressive acquisition of competences and skills. A conceptualization that allows the child to be an active participant in the process of social reproduction is that of a web, which is centered on the family of origin, but which acknowledges children's active participation in a range of other institutional locales that bring them into contact with other children and adults that are not family members. Indeed, "[i]t is in these institutional fields, as well as in the family that children begin to produce and participate in a series of peer cultures" (Corsaro 2005: 25). From this perspective, we can view children's norms and everyday practices as having an important structuring role in the suburban locales that they call home.

The data drawn on in this article was collected in the course of the New Urban Living Study, an investigation of civic and social life in the suburbs around Dublin conducted between 2002 and 2004. Four different suburban locations were selected for inclusion in the study (see Table 1). In each locality a random sample of 200 residents living in suburban estates was interviewed. In addition, in-depth interviews were conducted with key informants and focus groups were con-

Table 1 - Sample of Suburban Locations

\begin{tabular}{|c|c|c|}
\hline Suburb & $\begin{array}{l}\text { Distance from } \\
\text { Dublin city center }\end{array}$ & Profile \\
\hline $\begin{array}{l}\text { Leixlip, } \\
\text { Co. Kildare }\end{array}$ & $15 \mathrm{~km}$ & $\begin{array}{l}\text { Mature suburb that grew rapidly in } \\
\text { the } 1980 \text { s but has stabilized since } \\
\text { then }\end{array}$ \\
\hline $\begin{array}{l}\text { Lucan, } \\
\text { Co. Dublin }\end{array}$ & $12 \mathrm{~km}$ & $\begin{array}{l}\text { Suburban area that grew rapidly in } \\
\text { the } 1980 \text { s and has continued to } \\
\text { expand rapidly since then }\end{array}$ \\
\hline $\begin{array}{l}\text { Mullingar, } \\
\text { Co. Westmeath }\end{array}$ & $80 \mathrm{~km}$ & $\begin{array}{l}\text { Provincial town that has undergone } \\
\text { rapid suburbanization on its } \\
\text { perimeter since the } 1990 \text { s }\end{array}$ \\
\hline $\begin{array}{l}\text { Ratoath, } \\
\text { Co. Meath }\end{array}$ & $25 \mathrm{~km}$ & $\begin{array}{l}\text { Small village that began to rapidly } \\
\text { expand in the } 1990 \text { s, becoming the } \\
\text { fastest growing village in the region } \\
\text { between the } 2002 \text { and } 2006 \\
\text { censuses }\end{array}$ \\
\hline
\end{tabular}


ducted with local residents. In order to document the views of children growing up in each locality, we identified the schools closest to the suburban areas under investigation. We wrote to the principals of those schools seeking permission to speak to sixth-grade students about their experiences of growing up in suburbia. We chose to focus on a preadolescent cohort (11 to 12 years old) because their everyday social reality is primarily structured through family, school, and locality. We felt they would have a unique insight into the processes through which acquaintanceship, friendship, and sociability are generated in suburban housing estates. Because they had not yet made the transition to secondary school (which would require many of them to travel out of the locality), these children's main reference points were local. Hence, they could provide a perspective on the suburbs different to that of teenagers, adults, and older residents who travel independently out of the locality for school, work, college, and leisure purposes.

The relevant teachers obtained consent from the parents or guardians of children in sixth grade to participate in the research. In some cases the teachers prepared the students for our visit by getting them to write short essays titled "The place where I live." Two researchers attended each focus group, one to facilitate the discussion and the other to take notes. The sessions generally lasted between 30 and 40 minutes per focus group. We explained the purpose of the research to the children and the value of eliciting their unique perspectives. Topics covered included the locality, family, friends and neighbors, facilities, use of technology, and personal aspirations. We assured the children of the confidentiality of the research process and protection of their identities. Tapes of the focus groups have been kept in a locked cabinet. All identifying names were removed prior to transcription stage. Participation in the research involved no risk to the children. Rather, participation could be seen as a benefit in that it gave them an opportunity to air their views on a range of topics about which they would not normally be consulted. It was necessary however to address their expectations and to make clear that though the researchers were investigating suburbia, we had no power to change things that affected their daily lives. See Table 2 for data collected from the children.

Part of our concern in conducting focus groups was to ascertain how "good" an experience childhood is in new suburban communities, and in particular to establish how the neighborhood impacts on children's well-being and future. To this end we adapted our methodological approach in order to "explore how children themselves actively generate, draw on, or negotiate their own social capital, or indeed 
Table 2 - Sample of Schools

\begin{tabular}{|c|c|c|c|c|}
\hline Place & School & $\begin{array}{l}\text { No. of } \\
\text { focus } \\
\text { groups }\end{array}$ & $\begin{array}{l}\text { No. of } \\
\text { participants }\end{array}$ & $\begin{array}{l}\text { No. of } \\
\text { essays }\end{array}$ \\
\hline $\begin{array}{l}\text { Leixlip, } \\
\text { Co. Kildare }\end{array}$ & $\begin{array}{l}\text { School Mhuire/ } \\
\text { Scoil Bride N.S. }\end{array}$ & 6 & 57 & 30 \\
\hline $\begin{array}{l}\text { Lucan, } \\
\text { Co. Dublin }\end{array}$ & $\begin{array}{l}\text { St. Anne's N.S./ } \\
\text { Archbishop Ryan, N.S. }\end{array}$ & 4 & 38 & 24 \\
\hline $\begin{array}{l}\text { Mullingar, } \\
\text { Co. Westmeath }\end{array}$ & St. Colman's N.S. & 6 & 60 & 67 \\
\hline $\begin{array}{l}\text { Ratoath, } \\
\text { Co. Meath }\end{array}$ & Ratoath N.S & 6 & 72 & 81 \\
\hline Total & & 22 & 217 & 202 \\
\hline
\end{tabular}

make links for their parents, or even provide active support for parents" (Morrow 1999: 751). Our study takes into account the transactional nature of the relationship between children and community within the suburban neighborhood, because we allow for the fact that each has the capacity to influence and to be influenced by the other.

This article concentrates on the child's relationship to and perception of three environments in particular: the estate, the local neighborhood, and the metropolitan core. As children venture out from the home into their estate and the wider neighborhood they have the potential to play a significant "civil integration" role (Vertovec 2007). This is because their everyday interactions in the spaces beyond the private sphere helps to bring adults into contact with each other and create a social structure that is rooted in locality. Children's movement through suburban space and the circuits of sociability they generate represent an important part of the social glue that holds new suburban communities together. At the same time, their freedom of movement and right to autonomy are increasingly compromised by the undermining, and in some cases disappearance, of public arenas for the enactment of those freedoms.

\section{Children, Place, and Space in Suburbia}

Children appropriate the suburban landscape in particular ways to suit their needs for association and adventure. They create special meet- 
ing points and hanging out spaces that provide them with opportunities for sociability and interaction with other children from within and beyond their estates. This is not always a positive process, because some residents view the presence of a large number of children locally as a nuisance factor and complain about the kicking of soccer balls into gardens or the congregation of teenagers in one particular part of the locality. But from a child's point of view, the capacity to make the estate and the wider locality their own is a crucial part of their personal development (Hart 2006; Jones 2000). The kind of chance interactions that take place in public space also provide a context within which children can develop and refine the principles of civility and the practice of good citizenship.

Stephens (1995), however, has called attention to the erosion of childhood environments and what this has meant for children, their well-being, and the nature of childhood itself. As local space is compromised through unfettered development, the degree to which children can feel safe in their locality, and the degree to which they can develop a sense of place attachment may be undermined. Children and their parents are required to balance concerns about personal safety against their freedom to inhabit public space. Too much focus on safety results in a disengagement from public activities and the use of public space. Conversely, parental anxieties increase when children move beyond the orbit of surveillance immediately beyond the hall door.

Risk has been identified as a central condition informing contemporary society (Beck 1992; Giddens 1991). In general, industrialization and the development of modern systems of protection (material security, policing, insurance, health and safety measures) have reduced risk. But they have also heightened awareness of risk partly because such heightened awareness is usually considered an essential element of improved protection. The awareness of and sensitivity to risk shapes the discourses that emerge around children and childhood (Bonner 1997). The contemporary construction of the child as vulnerable and in need of protection permeates all levels of the class structure, providing a basis for adults to negotiate and control children's access to and use and experience of public space (Valentine 1996). Analysts have argued that "risk anxiety is a constant and pervasive feature of everyday consciousness, managed through everyday practices" (Scott et al. 1998: 690). Nevertheless, the perception of risk and the intensity of risk are likely to vary across urban (perceived as risky), suburban (less risky), and rural neighborhoods (risk free). Indeed, accounts that chil- 
dren give of everyday life in risky neighborhoods (see Corcoran 1998, 1999; Kelley et al. 1997; Spilsbury 2002) amply demonstrate how the naturalization of the concept of childhood serves to mask the extent to which there are plural childhoods "shaped and differentiated by the inequalities of class, gender and ethnicity" (James and James 2001: 214). Many parents move to the suburbs or to the countryside because they perceive them to be safer and better places to raise kids. They seek village-type communities where people are friendly with each other and where there is low-key, low-level surveillance. Children, thus, can be protected from the problems associated with big-city living, and the risk of growing up too quickly. However, in the suburban localities under investigation, a number of problems emerged - such as anti-social behavior by teenagers, heavy traffic, and lack of basic amenities in the area-which lead to increased rather than reduced anxiety among the local adult population. In other words, although suburbia holds out the promise of a more risk-free environment, it generates its own risks, which inevitably impact on the degree of the child's autonomy. Below we explore how this tension manifests itself and works itself out in the everyday lives of Irish children growing up in suburbia. The analysis is derived from children's own understanding of risk and risk-related decision making, because it is likely that children's construction of their own social position and their understanding of their own experiences may differ from those of their parents. We begin by looking at children's perceptions of the estate, which forms the link between their private homes and the more public world of the neighborhood.

\section{Sociability Networks: The Role of the Estate}

Research suggests that children reflexively construct their landscapes of risk and safety around concepts of private, local, and public. Although children describe the private sphere of home in terms of safety and security, they express concerns about their vulnerability in public space. The literature suggests that children perceive a third or intermediate sphere between private and public-identified in terms of proximity to home and familiarity with places and people (Harden 2000). Feelings of personal safety then are closely linked to the degree of local knowledge and attachment to local people and place.

The social neighborhood-the face-to-face community of neighbors - is a micro-structure, which emerges among small clusters of 
neighboring dwellings and which is likely to arise in a number of different forms even within relatively small areas. According to Blokland, "quite simply, a neighborhood is a geographically circumscribed, built environment that people use practically and symbolically" (2003: 213). The kinds of neighborhoods we are dealing with in this study are largely constituted by a number of proximate suburban estates configured around an existing settlement such as a village or small town. Neighborhoods do not encompass all residents equally because not all residents make them the focus of their encounters, interactions, and transactions. Historically, suburban neighborhoods have relied for their vitality primarily on social ties among the daytime population. With the exception of Leixlip, the oldest of the four suburbs under investigation, our study localities are characterized by daytime populations made up primarily of full-time and part-time mothers with young children. Not surprisingly, for many suburbanites it is precisely at the stage of family formation that the pull of the suburb becomes most appealing. The choice of suburb is in turn frequently a function of social class, with income determining the nature and type of house that can be purchased and its location (see Bonner 1997; Salamon 2001).

Neighborliness and the urge to connect with people around us are part of a fundamental human need to bond. As Buonfino and Hilder observe: "[i]ndividuals tend to socialize, and despite the changing family structures and work-life balances, people will always be drawn to other people" (2006: 4). Indeed, our study found that the way in which suburbs develop and evolve both in terms of their social and physical infrastructure are closely tied to the needs of children. For example, in each of our four localities we found strong support for local amateur sports clubs, ${ }^{i}$ which provide structured leisure time outlets for families in suburbia. However, in tandem with this focus on providing for children we must also acknowledge that children themselves, acting as agents in their own right, typically provide an important focus of social interaction locally. This is both because of their own interactions with other children living close by (a form of neighborliness in itself) and because they actively draw their parents into contact with the other children's parents.

Neighborhoods with children tend to be more neighborly than others (Buonfino and Hilder 2006). Networks of parents structured around the circulation spaces of children are among the more common and stronger forms of neighborhood micro-communities. According to Volker and Flap (2005), meeting opportunities are a crucial precondition for establishing a sense of community in a neighborhood. Shops, 
recreation facilities, schools, parks, and churches become meeting points for people to get together (see also Fischer et al. 1977). The more facilities there are in a neighborhood, the greater the chance people will become affiliated with others in the process generating a sense of communality.

The suburban housing estate is a discretely identifiable geographic space, which is of particular significance to children. It constitutes the immediate social environment where they are likely to spend time outside of the family home. In writing about "The place where I live" most children across the four localities wrote about the configuration of their own home and then the surrounding estate. The boundaries of the housing estate are usually marked by an entryway in the form of gateposts (without gates) or a stone with the name of the estate engraved on it. Houses tend to follow a standard design with front and back gardens. Landscaping within the estate generally includes a number of green areas, the functionality of which varies from estate to estate. Children singled out green areas in their respective housing estates as being places they enjoyed and utilized for social and recreational purposes. Soccer, in particular, was played frequently and there was a general consensus that the greens were a focal point for meeting other children and for generally having fun. The green itself or a designated area similar to a green within or adjacent to the estate is the key point of congregation.

\footnotetext{
When I walk down the footpath there is a field at the end of the road. There are football goals so I play football down there and every so often there are horses down there. Every summer there are races around the green and whoever won $[s i c]$ receives a medal. (School child, Mullingar)

My place is full of kids. And in the estate there is a tree where some of the kids go. We call it a tree house (School child, Leixlip).

There are big fields behind my house and sometimes I play in them. In the summer there are the community games held on the green ... On warm days people play football on the green. (School child, Mullingar)
}

Children tended to move in and around different estates to meet up and play with friends. The abilty to move beyond the boundaries of a particular estate is indicative that the surrounding environs are generally viewed as safe, and access on foot or bicycle to the main street of the village is possible. In two of our localities we came across instances where one estate leads through pedestrian walkways into another, and crucially, children do not necessarily have to cross any main roads. The estates follow a physical layout that encourages con- 
nectedness. The estates we surveyed in Leixlip and the mature estates in Lucan-home to some of the children we consulted in one of the local national schools - most closely emulate the model of Levittown, the planned community on Long Island, New York, where children of school age walk to the neighborhood primary school and extend the range within which they visit friends and schoolmates by using bicycles (Popenoe 1977: 187). This is significant because research on sustainability and suburban development has demonstrated that lack of pedestrian movement reduces social contacts and slows down processes of community building (Gwillam et al. 1999: 13).

In the newer suburban estates of Mullingar, Lucan, and Ratoath where development is ongoing, freedom of movement is somewhat more curtailed. New estates are designed around car mobility rather than walkability, and most people overwhelmingly rely on cars as their primary mode of transport, a situation which in turn exacerbates traffic problems. In these newer suburban developments, estates are often bisected by busy access roads. Additional traffic and activity is associated with continued development giving an "unfinished" quality to the local environment, and creating real risks for children traversing the roads and pathways. Not surprising, this creates legitimate concerns among the local populations about congestion, air quality, noise, and public safety on roads (see Gwillam et al. 1999: 13). Furthermore, the continued development results in the disappearance of different kinds of "meeting places" leaving the locality bereft of inbetween, interstitial spaces where children can hang out. As we shall see, this was a major annoyance for the children consulted in the course of this study. The proliferation of the suburban estate was found to have real consequences for the availability of "free play" space and for the freedom of movement of children.

Children see the estates as their primary arena of sociability after school. Indeed, friendships at school are reinforced through play that continues on the green and in and around the estates. They also allow children to extend the range of their friendship networks beyond suburban space itself. Children who live outside the suburban developments also see these estates as centers of sociability, and use every opportunity to play there.

I live out in the countryside like, and there's no children out there so I have

to go up to the estate to be with friends. (School child, Mullingar)

As the following exchange testifies, the green is the magnet that allows for movement of children around and between estates: 
Respondent (school child, Mullingar): And there's more people that live in Tranmore [estate] and they're always in our areas for football and stuff and the fact that we don't have too many kids in our area, only two or three ... so they are using our green to play football.

Interviewer: So one group from one estate will come over to play another?

Respondent: Yeah to play another

Interviewer: So do the estates get on quite well with each other then?

Respondent: Bit of rivalry playing football but that's about it, but we still get together to try and get a game going.

Similarly, children in Ratoath reported that a particular ploy often employed in order to extend the circle of friends or welcome someone new into an established group of friends in the estate was to have a game of football and ask the newcomer(s) to join in. Children attending national schools in Lucan and Ratoath commented that the existence of a large number of estates in their neighborhoods ensured a high number of friends. Relatively high density, proximate developments configured around quality green areas enable local children to widen their pool of potential friends. Variations in estate design mean that some estates have green areas that are better suited to communal games such as football and rounders than others.

It is also noteworthy that estates that are more or less clearly physically demarcated from each other (by entrance gates, introverted culde-sac design, etc.) may set symbolic boundaries to the extent of the sociability network in the neighborhood, encouraging intensive rather than extensive circuits of sociability. Although suburban housing estates may all look the same, subtle variations in design make some estates more child-friendly than others. From a child's perspective, estates with well tended, central greens are preferable to those without. Estates that can be accessed through walkways encourage inter-estate connectedness whereas those accessible through roadways only do not.

Children also view space on the estate as a resource upon which different claims are made by different groups. Particular groups may have priority in relation to different elements of the greens.

\footnotetext{
There's the green where people play football and the rockery is where everyone hangs around. The other green is not used for big football matches only world cups or "beat the keeper," but that green is mainly used for hanging around. ... There are some groups of people that hang around with each other, there is the football fans (the biggest group), the skaters and rockers, the wrong group, and the young group (that's the group that I am in!). (School child, Leixlip)
} 
If the green acts as a magnet for sociability, other features of suburban design may act as deterrents. A poorly designed green is a liability. Children recognize that such a green is not intended for play and that it may be just transient space that is earmarked for other uses.

There's a green with a hill on it so you can't play football. The other green has been dug up. More houses are still being built. The roads are uneven and there's dirt everywhere because of the construction. (School child, Mullingar)

Poor maintenance may seriously affect the viability of a green area, and as a result cut children off from a local sociability circuit.

Most of my friends live in [estate] When I go over to [estate] the green is full of glass and broken metal. (School child, Lucan)

On my road we have a green area it is kind of boring because we did have goal posts but some people wrecked them. A lot of cars on my road parks out on the road even though they all have driveways. (School child, Mullingar)

Run down or poorly managed greens are unusual in most privately developed estates as residents generally co-operate to assume the management of the greens. Though this ensures high levels of maintenance, it may also bring into sharp relief conflict between the aesthetic desires of adults and children's practical needs.

There is a green area and it used to have goal post but our chairperson took them down and now nobody plays on the green. (School child, Mullingar)

Our estate has a meeting every year and pick a new chair person the woman who is the chair person now gives out to us for playing soccer on the green. (School child, Mullingar)

Across all four suburbs in our study, estate greens are seen as crucial to local quality of life. The ideal estate from a child's perspective is one that is not too big, and is equipped with grass pitches and a nearby shop. Such estates are seen as an important alternative to formal club membership in the public sphere and the confines of a private back garden. The green represents for suburban children a kind of "third place" that is crucial to the maintenance of the community and the enhancement of social capital (Oldenburg 1989). It is a meeting place, an arena for sociability and a space for promoting civil integration.

\section{Curtailment of "In-Between" Public Space}

Despite the new "focus on the everyday spaces in and through which children's identities and lives are made and re-made" (Holloway and 
Valentine 2000: 11), surprisingly little attention has been paid to children in suburban space. The pathbreaking work by James et al. (1998) in developing a sociology of childhood focused in particular on three sites - the home, the school, and the city-as a means toward mapping the regimes of control, regulation, and learning imposed on children. The city, in this context, is interpreted as the urban streetscape that is not always accessible to children. In contrast, open space in suburbia such as the interstices between two estates, adjacent fields to new developments and local parks may be appropriated by children for their specific use in play or simply hanging out. Only a small number of studies, however, addresses this subject explicitly. Gans (1967) found that discontent among suburban youth in Levittown (United States) was related to their lack of spaces comparable to agrarian town public spaces. Lynch's (1997) study of children in a suburban neighborhood in Australia found that children who were denied the opportunity to create their own play space became bored and dissatisfied. Hart (2006) is critical of the provision of formal play areas and play grounds to the exclusion of less manicured, wilder, and more flexible landscapes that can provide a creative backdrop for suburban children.

In arriving at a definition of public space, Lownsbrough and Beunderman focus on the notion of accessible spaces characterized by low barriers to entry: "public spaces should be cost free, with no requirements of users and certainly no exclusion on the grounds of gender, race and so on" (2007: 11). For Richard Sennett (2005), the public realm is a place where virtual strangers can meet in safety. The availability of public spaces in a given locality are important for several reasons. First, public spaces enable children's development by providing an arena in which they can interact with other children and form friendships. Also, public spaces act as meeting places and therefore contribute to the social capital stock in a community. Finally, public spaces help to build civility and citizenship because they encourage inclusiveness and coresponsibility (Hart 2006). Public spaces, as Hart states, are important non-formal and non-programmed settings for the participation of children. There is, however, a problem of free access to public spaces because of the entrapment of children partly fueled by discourses of risk in the wider society. Concerns about child protection and child safety have become central to discourses of risk.

On the one hand, parents seek to minimize risk by ensuring that their children grow up in a safe environment. The desire to raise children in such an environment is a major motivational factor underly- 
ing the move to the suburbs. However, if aspects of that environment are deficient (e.g., heavy traffic on the roadways, absence of safe footpaths or cycle paths, etc.), parents continue to worry about the safety of their children. On the other hand, children, acting as agents and freed (at least temporarily) from parental control seek to roam the public spaces in and around their neighborhoods, and make the neighborhood their own, marking out territory, creating "hanging out" spots, and "arenas for doing nothing." Indeed, there is considerable evidence that "children's own sensations of fear, anxiety and excitement are associated with the crossing of those temporal and spatial boundaries which serve to define their place within family and locality" (Scott et al. 1998: 695). Children in suburbia, much like children everywhere, are caught between two potentially conflicting forces. One force promotes ideas about being safe and protected (and being indoors or close to home or always contactable by mobile phone); the other encourages them to inhabit their neighborhood as a public space that has particular attractions for them as they seek to move outside of their parents' orbit of control.

"Hanging out" is an important aspect of childhood socialization and marks a transition to adolescence in the lives of children. It provides an important outlet for learning how to develop and sustain social relations away from parental surveillance. It is while interacting with peers that teenagers develop "their own interactional competence, emotional expressions and cognitive constructs ... even as they navigate and resist adult authority" (Harrison and Morgan 2005: 94). Hanging out with friends was a favored pastime of children in our study, but increasingly their capacity to hang out in public space for the purpose of "doing nothing" was threatened by changes in the surrounding environment. All of the children expressed dismay at the extent of local development, which they saw as an irritant in several ways. They were critical, in particular, of noise pollution, the upsurge in traffic, and the disappearance of the countryside. The impact of development manifested itself then not only as a physical presence on the landscape, but also as a reminder of what was being lost to them in the locality.

In the case of all four localities, children perceived their localities to be changing in ways that potentially threatened their freedom of movement and right to congregate. The gradual transformation of the rural landscape made it at once less familiar and more threatening. Places for playing and hanging out-away from parental controlwere disappearing. 
Before you could see everywhere, you could see all the grass. Now all you can see around is houses and big buildings. (School child, Lucan)

There's a field near my house where the horses go and where you can play soccer but now they're building houses behind that. (School child, Mullingar)

There used to be a forest that we could go to all the time but now they're actually building on the forest and when you are near the forest, sometimes you can actually hear them building. (School child, Mullingar)

The Woodlands used to be a field where we could play but now it's gone [developed for housing]. The only walk is from the estate to the village along the road because pathways through the fields are gone. (School child, Ratoath)

The kinds of concerns expressed by adults in the survey about the consequences of overdevelopment were mirrored in the responses of the children in the focus groups and in their short essays. They bemoaned the concretization of their environment.

There is a new shopping centre and it is going to get a lot busier, and there are too much houses which are taking up too much space, because where all the estates are there used to be beautiful countryside and beautiful trees and animals but they are all gone. (School child, Ratoath)

Mullingar is getting a lot bigger, busier, traffic is heavier all around the place, the roads are getting dug up, a lot of houses, more people. (School child, Mullingar)

Lucan is far better than where I lived before, but the builders have got to stop digging up the whole of Dublin. (School child, Lucan)

I think that the committee should stop giving permission to the builders to build more houses because it is ruining the place and some of the animals are dying because of it. (School child, Ratoath)

Children's freedom to roam the wider neighborhood has become much more curtailed today than it was in the past. As in the past, children derive considerable pleasure from making "public places" in the neighborhood their own. Green spaces that are appropriate configured within the design of new housing estates, and that are managed well by local residents, certainly play a significant part in generating an arena for sociability. However, what is lost through much of the development are the in-between or liminal "hanging out" spaces where children can escape from parental control. This is regrettable from the point of view of the children, but inevitable in developerdriven suburbia. The rural dream that suburbia holds out for many parents (Bonner 1997) comes somewhat unstuck when the problems 
associated with the city-such as traffic, noise levels, pollution, and crime-follow them to the new idylls on the city's edge. A gap occurs between the "ideal" and the "real" suburb (Baldassare 1992: 479). Although the small, residential suburb with a country feel is preferred, most Irish suburbs (like their U.S. counterparts) have been in transition to large, diverse places in sprawling and increasingly congested regions (Baldassare 1986). The children are having to face the reality that the suburbs are becoming overdeveloped, altering their lived experience of the localities and restricting their access to open spaces.

Children have clear expectations with regard to their physical environment. They want it to offer them structure (as in a well-maintained green for formal game playing) and room for exploration and creativity. This reflects both their sense of adventure and their willingness to take risks as well as their desire to belong and be protected. Contemporary suburban design makes some (though limited) attempts to address the issue of providing for structured play, but remains adverse to retaining open, or interstitial spaces that have no apparent role or function. Such spaces are important because they facilitate social interaction and cohesion as well as allowing children to challenge social norms and boundaries and "test the limits" of society.

\section{Disavowal of the Urban}

A major motivation for people to move to the suburbs is the idea of escaping the city and its attendant problems. As Palen points out, "the suburban myth of the good life is predicated on urban ambivalence about, if not antagonism towards, cities and city life" (1995: 93). What is remarkable is the extent to which this anti-urban theme has been incorporated into the worldview of the children of suburbia, though many were born closer to the city, and maintain familial contacts there. They have developed a suburban sensibility that distances them from urban space. Generally speaking the children were primarily oriented toward their locality, and after that to other nearby locales. Only a minority of the 217 children who participated in focus group discussions, expressed an interest in visiting a downtown city facility when describing their perfect day out. Most wanted to either stay in their own locality playing with friends or visit adventure centers, shopping malls, skateboard, and motor tracks-all of which are located on the perimeter of the city. A clear pattern emerged across the four localities of people commuting between different towns and along the city's 
orbital route to access leisure and entertainment. The city, though it may be occasionally visited, is generally a negative rather than a positive reference point for suburban children. Many expressed the view that Dublin was a dangerous and crime-ridden place where one's personal safety is seriously compromised:

You need an adult because there are loads of drug dealers. (School child, Leixlip)

You would get robbed a lot in Dublin, my cousin got robbed, two lads came up and hit her and took her phone. (School child, Mullingar)

It's too dangerous with people robbing and all the cars. (School child, Lucan)

These fears are partly fueled by the idea that Dublin is overpopulated, and that the sheer force of the number of people proves to be a threat.

There are too many people, you could get separated from your Mam and Dad. (School child, Leixlip)

Dublin is too packed, full of thieves. (School child, Mullingar)

Not only is Dublin seen as anomic because of its "overpopulation" but it is also viewed as anarchic. Children express fears about being a random victim of crime, although in reality, the risk of being victimized in this way is extremely small.

There are kind of a lot of rough people there and they will beat you up for no reason. (School child, Leixlip)

I'm afraid of freaks with knives that might rape you. (School child, Leixlip)

Although they make reference to crime and criminality in their own localities, the children perceive it to be contained. It is an irritant, but not something that affects them unduly in pursuing their everyday lives. Their image of Dublin, however, is infused with mediated images of dangerous strangers stalking dangerous streets. This sense of trepidation about what might befall them when visiting the metropolitan core serves to reinforce anti-urban sentiments. The only positive note struck about Dublin was the fact that it offered an enviable supply of shops and some coveted leisure activities. Children were particularly enamored by the shopping and consumption possibilities of the city compared to the more limited offering in their own locales.

Dublin's deadly because of the shops. (School child, Leixlip)

Dublin is completely jam packed no matter where you go there's things to do. (School child, Mullingar) 
The city then holds very little attraction for these young children. Indeed, the suburban lifestyle adapted by their parents discourages a sense of connection with the metropolitan core. Links between the central city and the suburbs are relatively weak. Although Mullingar and Leixlip are connected to Dublin by train, the service is relatively limited, particularly during the weekends. There is no rail connection between Lucan and Dublin, and the efficiency of bus services is severely compromised by traffic and road construction disruption. Ratoath has poor public transport links with Dublin because it lies beyond the metropolitan hinterland served by Dublin Bus. Not surprisingly, the majority of adults consulted in the survey do not use public transport. Hence, children are not socialized into the use of public transport and come to rely on cars as a mode of transport. Furthermore, it is easier for the children to access large suburban shopping malls, which offer them opportunities for shopping and entertainment, without being accompanied by an adult.

Malls are policed private space, and young people may feel safer there than on public streets. It is likely that the parents themselves who tend to access goods and services in different locations within the suburban hinterland (rather than the city) feel more comfortable about allowing their children to be in these spaces. Shopping in the city is something that is done with parents or other adult guardians on special occasions. No child spoke about attending an arts or cultural event in the city, even though cities tend to be much richer in these kinds of cultural resources than suburbs. The withdrawal of suburbanites from the city streets and the association of the city with crime and incivility are redolent of the well-documented relationship between the suburbs and the urban core in the United States. The reproduction of this antiurban ideology across the generations in the Dublin suburbs raises pertinent questions about the long-term vitality of the metropolitan core.

\section{Conclusion}

Ratoath, even the name is historic "Rath to" in Irish the Moat, Fairyhouse race course, the scenery, the ever growing village! Ah, what an easy place to settle into. Here you feel like part of a community with annual runs and walks and kids at your door looking for money looking for charity although whether you like the last one is up to you. Somehow you just feel like this is home, this is where the heart is (School child, Ratoath). 
The emphasis in geographic work on place is not only useful in reminding us that conceptions of childhood are spatially as well as temporarily specific (Holloway and Valentine 2000: 10). Research of this kind also shows how children are important in creating their own cultures and life world. Children in suburban localities essentially operate within residential spheres. More than their parents or other adults in the vicinity they are confined to their immediate neighborhood. These residential spheres do not necessarily correspond to formal neighborhood boundaries, but "are the outcome of a process of mental mapping and identification with specific places" (Lupi and Musterd 2006: 814). This mental mapping colors how children perceive the immediate environment of their estates and the proximate environment of the neighborhood in which the estate is embedded. Our research suggests that children growing up in suburbia develop such mental maps, partly through socialization but also as a result of their own investigation of their residential sphere. They are most at home in their own estate where feelings of belonging are reinforced through friendship and neighborly networks. Interaction with children from adjacent estates extends their sphere of activity beyond their own immediate estate. Children effectively act as agents of "civil-integration" (Vertovec 2007) through their mobility in and through neighborhoods, and through the circuits of sociability that they create.

Hanging out together and away from parental supervision is possible in public spaces or "wild zones" that are dotted between estates, in and around the "back stage" of the village center or outside the shops on the main streets of Mullingar, Ratoath, Lucan, and Leixlip. Public spaces, however, appear to be under threat from continued development and this is a point of contention for the children. Indeed, an international review has observed that the number of spaces that may be deemed unambiguously "public" are dwindling (Lownsbrough and Beunderman 2007: 14). As Hart (2006) has observed, when roads go into a neighborhood free play disappears, and middle-class children become segregated behind walls. This observation is eloquently echoed by one of our informants: "Trees are knocked down just to make walls and you don't even need walls when you have the trees" (School child, Ratoath).

Lack of access to such spaces is storing up problems for the future. Discontent among suburban youth is related to their lack of spaces comparable to agrarian town public spaces (Childress et al. 1996; Gans 1967). In a risk aware society, parents develop anxiety about the 
safety and well-being of their children. This encourages them to keep their children under informal surveillance. At the same time, the disappearance of public space in these new suburban developments limits the potential of children to range freely across the locality. The opportunity to exercise freedom of movement away from adult surveillance is increasingly replaced by participation in programmed and supervised activities. Hart (2006) advocates the creation of unpoliced "wild spaces" that interrupt the planned landscape of suburbia and offer truly child-friendly communities, within which children can develop. What children want is the retention of "in-between" or interstitial green spaces in their immediate locality that have no defined role or use but that they can use in different ways. There is little evidence, however, that either planners or developers are prepared to take such a child-centered perspective into account while creating new suburban communities (Gleeson 2008). It appears as if suburbs are set to repeat a trend toward social dissociation already underway in cities, which are characterized by "increasing provision of segmented spaces based on self selection and focusing on a narrow range of activities" (Lownsbrough and Beunderman 2007: 13). Conventional urban planning strategies tend to be preoccupied with the structuration of space (e.g., the development of "staged" arrangements that purport to meet the needs of particular age groups. Indeed, there is considerable preoccupation in the suburbs with providing for children's needs, through access to playgrounds, sports, leisure facilities and other amenities, described rather aptly by Qvortrup as "planned spontaneity" (1991: 29-30). Although a major motivation for moving out of the city is to raise children in a more pleasant, country-like environment, in reality parents end up expending considerable time and energy organizing activities for their children and in most cases, ferrying them by car to and from activities.

In general, the children in our study express a strong preference for suburban over urban living. These findings are similar to those of a recent study of two suburban localities in the Netherlands. There, researchers found that suburban youngsters were happy with their living situations and expressed strong social and habitual ties. As is the case in Ireland, these young people had also internalized a suburban ideology, along with a critique of nuisances and environmental degradation in their immediate neighborhoods (Lupi and Musterd 2006: 814). As Lupi and Musterd suggest, it seems that suburban life is "emblematic of modern, transformed social cohesion" (2006: 809). As we 
have shown, this process of "becoming suburban" is a key part of the socialization process of children, but children in turn play a significant constitutive role in the everyday social life of suburbia.

\section{Acknowledgments}

This article is based on the New Urban Living project, which was supported by grants from the Royal Irish Academy and from the Katherine Howard Foundation. The project was also supported by the National Institute for Regional and Spatial Analysis at the National University of Ireland, Maynooth. For further details on the study, see the authors' forthcoming volume from Syracuse University Press, Suburban Affiliations (2009).

Mary P. Corcoran is Professor of Sociology, at the National University of Ireland, Maynooth, where she is also a research associate at the National Institute for Regional and Spatial Analysis. She is a graduate of the University of Dublin, Trinity College, and Columbia University, New York. Her research and teaching interests are in the fields of urban sociology, public culture, and the sociology of migration. Corcoran has been involved in a number of international projects focusing on urban deprivation and urban regeneration. Her most recent work is the edited collection (with Perry Share) Belongings: Shaping Identity in Modern Ireland (2008).

Dr. Jane Gray is a Senior Lecturer in the Department of Sociology at the National University of Ireland, Maynooth. She is a research associate at the National Institute of Regional and Spatial Analysis and Director of the Irish Qualitative Archive. Her research and teaching interests include families and households, comparative-historical sociology, life history analysis. Her current research focuses on life histories and social change in twentiethcentury Ireland; family and community in contemporary Irish suburbs; gender, household economies, and social change.

Michel Peillon is Professor of Sociology at the National University of Ireland, Maynooth. He has co-edited five volumes of the Irish Sociological Series. His research interests include stratification and class, state and political life, social movements, welfare, and immigration. He is currently engaged in the study of urban living, the social appropriation of urban space, collective life in the suburbs, and urban social movements. 


\section{References}

Baldassare, Mark. 1986. Trouble in Paradise: The Suburban Transformation in America. New York: Columbia University Press.

Baldassare, Mark. 1992. "Suburban Communities." Annual Review of Sociology 18 (1): 475-94.

Beck, Ulrich. 1992. Risk Society: Toward a New Modernity. London: Sage.

Blokland, Talja. 2003. Urban Bonds, Cambridge: Polity Press.

Bonner, Kieran. 1997. A Great Place to Raise Kids: Interpretation, Science and the Urban-Rural Divide. Montreal and Kingston: McGill Queen's University Press.

Buonfino, Alessandra, and Paul Hilder. 2006. "Neighbouring in Contemporary Britain." Report for the Joseph Rowntree Foundation Housing and Neighbourhoods Committee. York: Joseph Rowntree Foundation.

Buonfino, Alessandra, and Geoff Mulgan. 2006. Porcupines in Winter: The Pleasures and Pains of Living Together in Modern Britain. London: Young Foundation.

Corcoran, Mary P. 1998. Making Fatima a Better Place to Live. Dublin: Fatima Groups United.

Corcoran, Mary P. 1999. "Social Structure and Quality of Life." Pp. 125-48 in Social Housing in Ireland: Success, Failure and Lessons Learned, ed. T. Fahey. Dublin: Oak Tree Press.

Corsaro, William. 2005. The Sociology of Childhood. 2nd ed. Thousand Oaks CA: Pine Forge Press.

Fahey, Tony, ed. 1999. Social Housing in Ireland: Success, Failure and Lessons Learned. Dublin: Oak Tree Press.

Fischer, Claude S., Robert Jackson, Ann C. Stueve, Kathleen Gerson, and Lynne McCallister Jones. 1977. Networks and Places. New York: Free Press.

Gans, Herbert J. 1967. The Levittowners. New York: Pantheon.

Giddens, Anthony. 1991. Modernity and Identity. London: Polity Press.

Gleeson, Brendan. 2008. "Child Friendly Cities and Urban Spaces." Paper presented at the Irish Social Science Platform Summer School, Institute of Technology, Sligo, Ireland, 23 June.

Gwillam, Michael, Caroline Bourne, Corinne Swain, and Anna Prat. 1999. "Sustainable Renewal of Suburban Areas." Report for the Joseph Rowntree Foundation. York: YPS in association with JRF.

Harden, Jeni. 2000. "There's No Place Like Home: The Public/Private Distinction in Children's Theorizing of Risk and Safety." Childhood 7 (1): 43-59.

Harrison, Tyler H., and Susan E. Morgan. 2005. "Hanging Out Among Teenagers: Resistance, Gender and Personal Relationships." Pp. 93-110 in Together Alone: personal relationships in public places, ed. C. Morrill, D.A. Snow, and C.H. White. Berkeley: University of California Press.

Hart, Roger. 2006. "Children and Public Spaces: How Adult Agendas Affect Children's Well-Being." Children's Research Centre Annual Lecture, Trinity College Dublin, Dublin, Ireland (October).

Holloway, Sarah L., and Gill Valentine. 2000. "Children's Geographies and the New Social Studies of Childhood." Pp. 1-26 in Children's Geographies: Playing, Living and Learning, ed. S.L. Holloway and G. Valentine. London and New York: Routledge. 
James, Adrian L., and Allison James. 2001. "Tightening the Net: Children, Community and Control." British Journal of Sociology 52 (2): 211-28.

James, Allison, Chris Jenks, and Alan Prout. 1998. Theorizing Childhood. Cambridge: Polity Press.

Jones, Owain. 2000. "Melting Geography: Purity, Disorder, Childhood and Space." Pp. 29-47 in Children's Geographies: Playing, Living and Learning, ed. S.L. Holloway and G. Valentine. London and New York: Routledge.

Kelley, Peter, Berry Mayall, and Suzanne Hood. 1997. "Children's Accounts of Risk." Childhood 4 (3): 305-24.

Lownsbrough, Hannah, and Joost Beunderman. 2007. Equally Spaced? Public Space and Interaction between Diverse Communities. London: Demos.

Lupi, Tineke, and Sako Musterd. 2006. "The Suburban 'Community Question'." Urban Studies 43 (4): 801-18.

Lynch, Kevin. 1997. Growing up in Cities. Cambridge, MA: MIT Press.

Morrow, Virginia. 1999. "Conceptualising Social Capital in Relation to the Wellbeing of Children and Young People: A Critical Review." The Sociological Review 47 (4): 744-65.

Oldenburg, Ray. 1989. The Great Good Place. New York: Paragon House.

Palen, John. 1995. The Suburbs. New York: McGraw-Hill.

Popenoe, David. 1977. The Suburban Environment: Sweden and the United States. Chicago: University of Chicago Press.

Qvortrup, Jens. 1991. "Childhood as a Social Phenomenon: An Introduction to a Series of National Reports." Eurosocial Report No. 36. Vienna, Austria: European Centre for Social Welfare Policy and Research.

Salamon, Sonya. 2001. Newcomers to Old Towns: Suburbanization. Chicago: University of Chicago Press.

Scott, Sue, Stevi Jackson, and Kathryn Backett-Milburn. 1998. "Swings and Roundabouts: Risk Anxiety and the Everyday Worlds of Children" Sociology 32 (4): 689-705.

Sennett, Richard. 2005. The Culture of the New Capitalism. New Haven: Yale University Press.

Spilsbury, James C. 2002. "If I don't Know Them I'll Get Killed Probably: How Children's Concerns about Safety Shape Help-Seeking Behaviour." Childhood 9 (1):101-17.

Stephens, Sharon. 1995. "Children and the Politics of Culture in Late Capitalism." Pp. 3-48 in Children and the Politics of Culture, ed. S. Stephens. Princeton, NJ: Princeton University Press.

Valentine, Gill. 1996. "Children Should Be Seen and not Heard: The Production and Transgression of Adults 'Public Space'." Urban Geography 17(3): 205-20.

Vertovec, Steven. 2007. "New Complexities of Cohesion in Britain: Super-Diversity, Transnationalism and Civil Integration." Report written for the Commission on Integration and Cohesion. http://www.compas.ox.ac.uk/publications/papers/ Vertovec\%20-\%20new_complexities_of_cohesion_in_britain.pdf (accessed 20 October 2008).

Volker, Beate, and Henk Flap. 2005. "When Are Neighborhoods Communities? Community and Solidarity in Dutch Neighborhoods." Paper presented the Civic and social life in the suburbs symposium, NUI Maynooth, Ireland, April. 